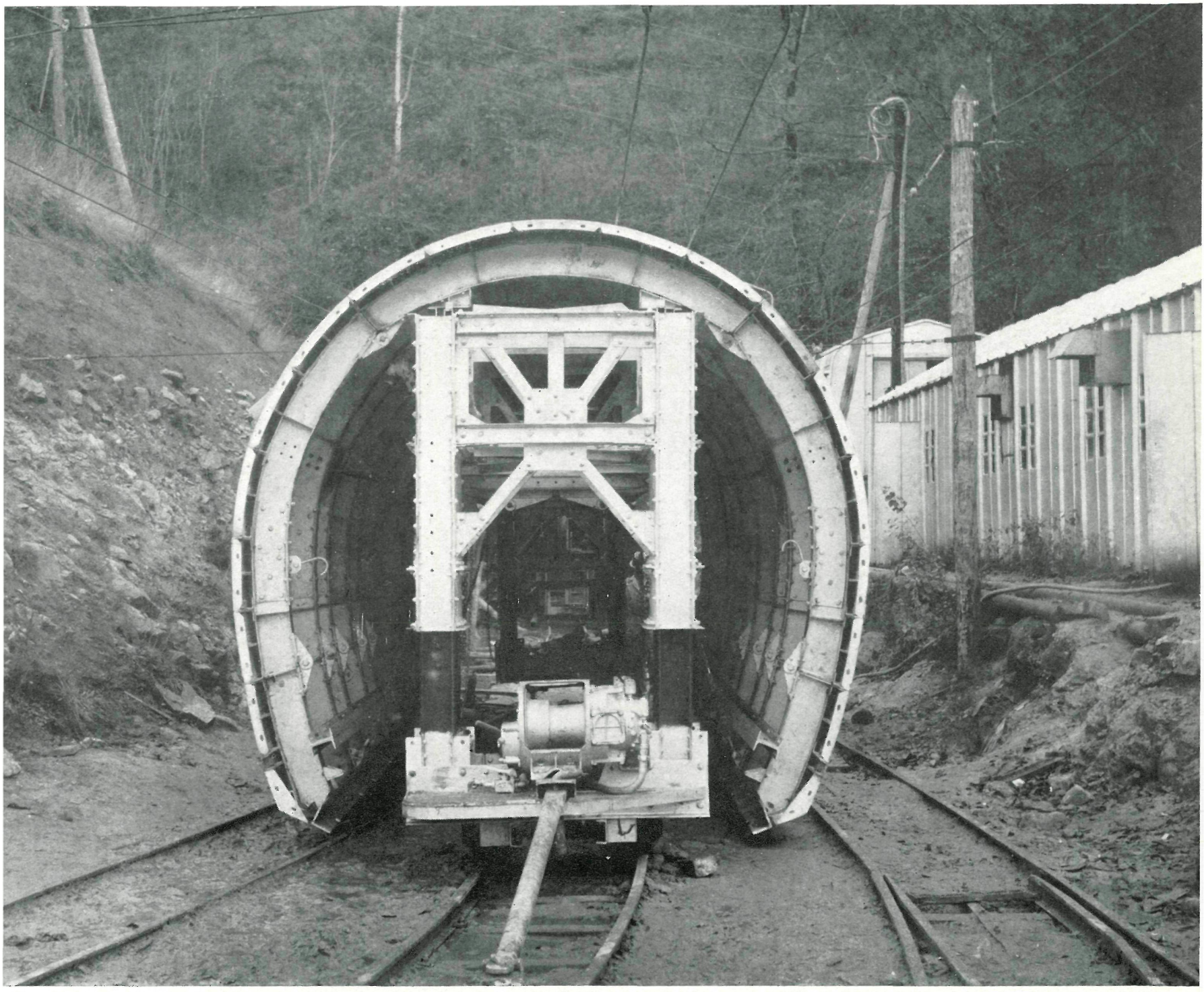

\title{
perforación y revestimiento de la galería de Laval de Cère II-Francia
}

Sinopersis

$532 \cdot 15$ El aprovechamiento hidroeléctrico de Cère II constituye un complejo importante que explota EDF. Situado en
el macizo central, montañoso, presenta las caracteristicas generales del tipo, esto es, aquí las galerias son la parte más importante.

Como su longitud es muy grande, todo el esfuerzo tiende a lograr velocidades máximas de avance, tanto en la perforación como en el revestimiento de galerías.

El autor estudia en este trabajo el material disponible capaz de lograr ciclos de repetición del menor periodo una descripción de los trabajos realizados y métodos empleados en cada caso concreto, es decir, en las zonas donde el terreno varía marcadamente.

Los medios de avance se han podido comparar fácilmente por ser dos las empresas a las que se adjudicaron las obras de la galería principal. 


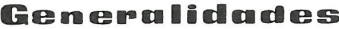

La galería de aguas abajo del complejo hidroeléctrico denominado Cère II, situadọ en el macizo central francés, propiedad de Electricité de France, ha sido subdividida en dos lotes, encargándose de la ejecución de cada uno de ellos dos empresas constructoras diferentes.

Uno de los lotes se compone de una ventana de acceso, de $330 \mathrm{~m}$ de longitud y $8.270 \mathrm{~m}$ de galería propiamente dicha. El otro lote arroja un total de 10 kilómetros.

Los trabajos adjudicados a las empresas constructoras se componían, en su totalidad, de la perforación y revestimiento, con hormigón ordinario, de una galería de $18 \mathrm{~km}$ de longitud.

La presencia de empresas diferentes en la ejecución de estas obras ha permitido establecer una serie de comparaciones de indudable significado experimental, tanto desde el punto de vista técnico como del económico.

\section{LA CERE}

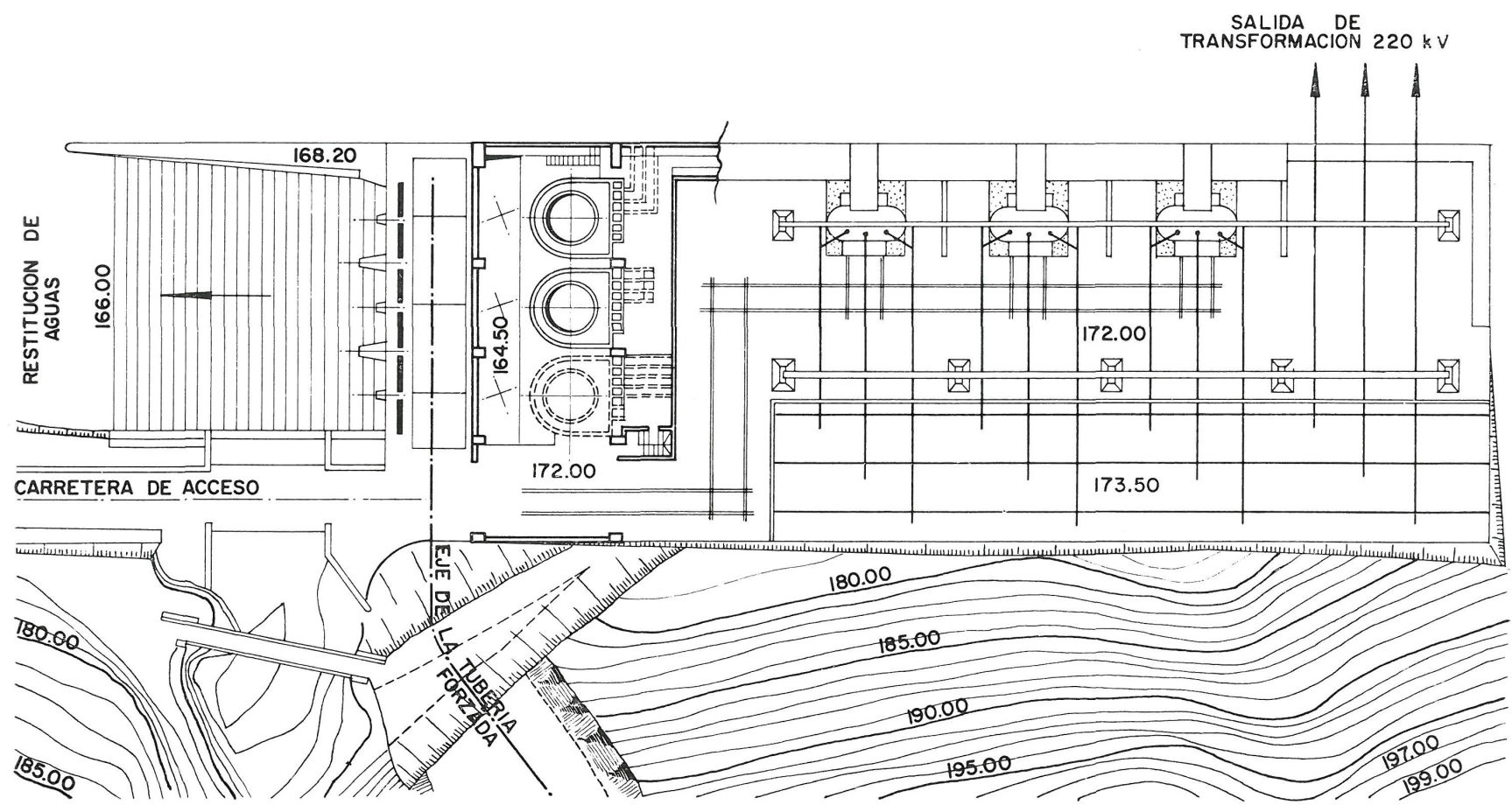

planta general 


\section{Perroración}

En todos los tajos de trabajo ha sido utilizado el sistema de cuele llamado canadiense, método que consiste en perforar una o varias cañas centrales que no se cargan. Estos taladros tienen su eje horizontal paralelo al de la galería.

El éxito de este dispositivo de tiro depende, en gran medida, del paralelismo de los barrenos cargados, situados alrededor de las cañas no cargadas, y a una distancia inferior de unos $150 \mathrm{~mm}$. El resto de los tiros ha de observar el mismo paralelismo, a excepción de los tiros de corona y hastiales, que reciben cierta ligera inclinación con objeto de permitir espacio suficiente para el martillo perforador.

Naturalmente, la perforación puede realizarse siguiendo métodos y procedimientos diferentes. La perforación ligera se realiza con martillos, soportados con tubos neumáticos, que empujan a aquél durante la perforación.

Los diámetros de los taladros así obtenidos varían de 32 a $36 \mathrm{~mm}$. Como las cañas no cargadas del cuele tienen diámetros superiores a los indicados, este tipo de perforación no es el más indicado para emplear el cuele canadiense.

La perforación pesada utiliza el «jumbo» y, con él, martillos con bocas de gran diámetro, que convienen para el cuele, pero no para el resto de los taladros, ya que para lograr un buen perfil y mejor troceo es necesario un número mínimo de barrenos.

Con una potencia de $500 \mathrm{CV}$. en los compresores y en una galería de unos $14 \mathrm{~m}^{2}$ de sección se ha obtenido, con la perforación pesada, un avance medio diario de $16 \mathrm{~m}$ y un avance excepcional de $21,20 \mathrm{~m}$ en un solo día y con 7 pegas, lo que constituye una cifra récord en Europa.

En el método de perforación semiligera persiste el empleo de martillos ligeros montados sobre brazos de un bastidor dispuesto sobre ruedas, que sustituye al "jumbo", y se dispone de un martillo pesado destinado a preparar el taladro no cargado, de gran diámetro, variable de 177 a $203 \mathrm{~mm}$. El chasis móvil utilizado en este método se denomina «Pantofore»; sus características principales son: sus distintos brazos, uno para cada martillo, y su disposición para adaptarse al perfil de la galería donde se le utiliza.

Como los avances medios logrados con la perforación semiligera son del orden de $15 \mathrm{~m}$ diarios, es decir, inferiores a los logrados con la perforación pesada, no cabe duda que, por lo menos en este caso, resulta más favorable.

Desde el punto de vista economía de mano de obra, el bastidor móvil semiligero hubiera resultado particularmente ventajoso de no haber sido defectuoso el material móvil utilizado en la extracción de escombros al exterior, lo que motivó la sustitución de este material móvil por otro de vagonetas, de $2,5 \mathrm{~m}^{3}$ de capacidad, de enganche automático, formando trenes de 12 unidades remolcadas por locomotoras Diesel, de 90 a $60 \mathrm{CV}$. de potencia.

La carga de escombros se realizó con palas mecánicas, tipo Atlas LM. 250, provistas con cuchara de 600 litros de capacidad. Los cruces de vagonetas se efectuaron por medio de cambios, modelo californiano, y dos trenes. La vía tiene $60 \mathrm{~cm}$ de trocha y los carriles son de $22 \mathrm{~kg} /$ metro.

Los ciclos de perforación se subdividen en la perforación propiamente dicha, que requiere de $1 \mathrm{hr}$ $15 \mathrm{~min}$ a $1 \mathrm{hr} 50 \mathrm{~min}$ según la presión disponible de aire; carga y pegas, unos $45 \mathrm{~min}$, y la evacuación de escombros, 1 hr 50 minutos.
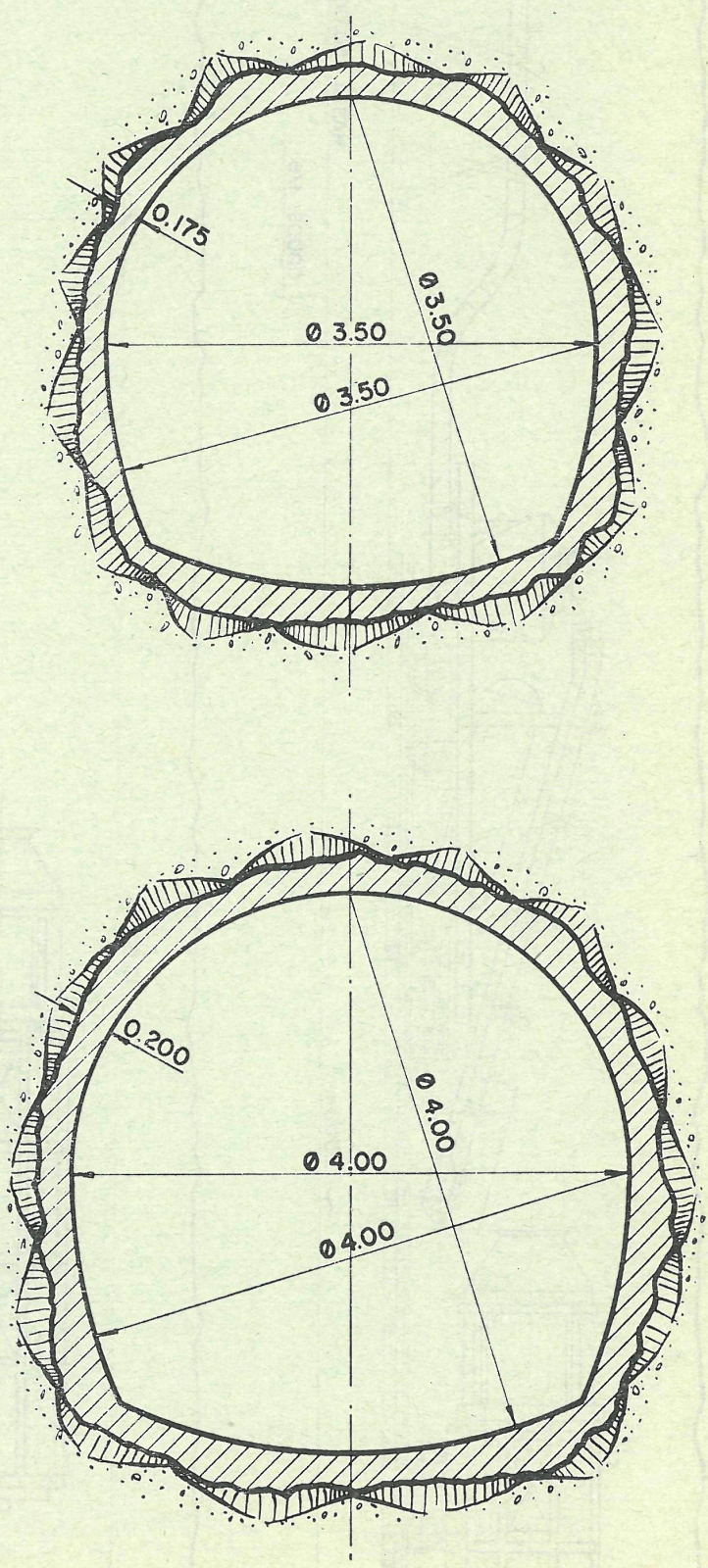

g a le ría 


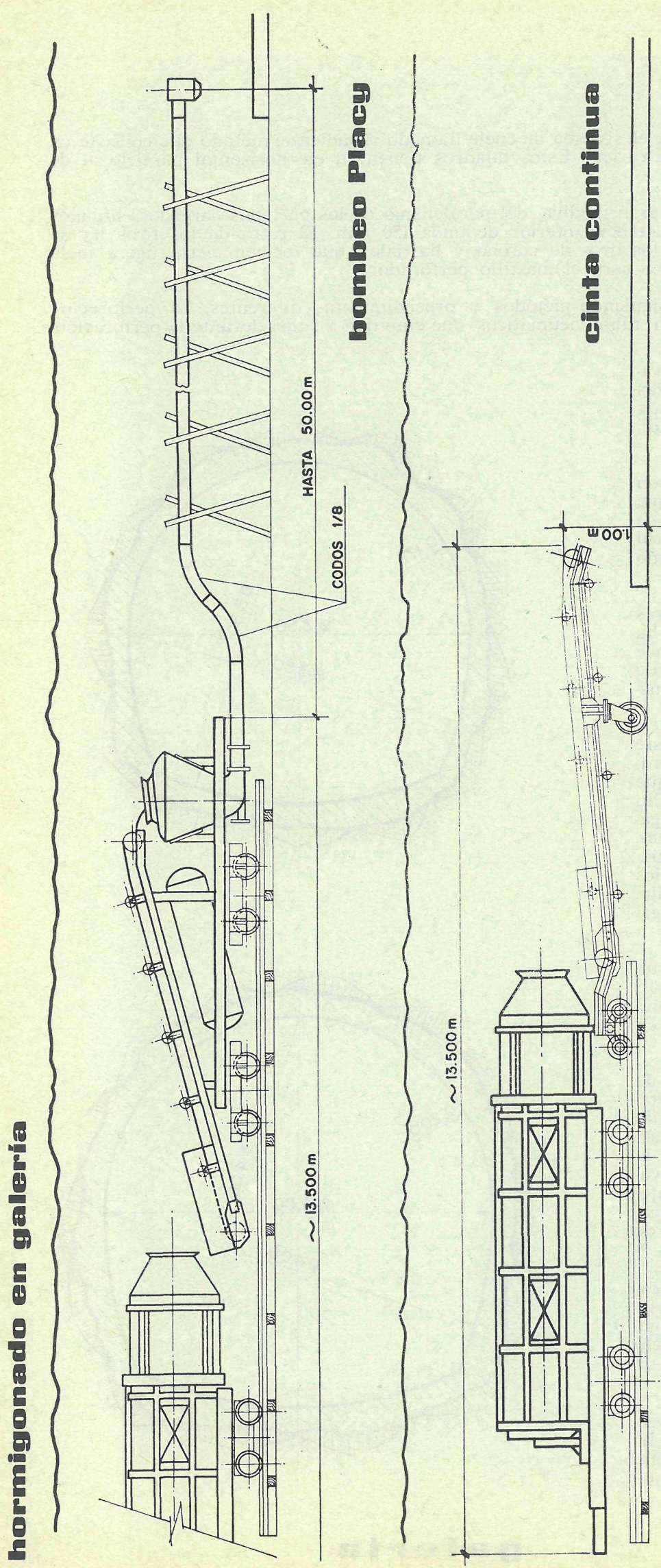

El consumo medio de explosivos en el frente de Salvagnac fue de $1,9 \mathrm{~kg} / \mathrm{m}^{3}$ de sofranex en roca sana y 2,3 a 2,4 $\mathrm{kg} / \mathrm{m}^{3}$ de goma A si se trata de roca dura.

En el otro lote, adjudicado a la empresa constructora Société Générale d'Entreprises, los avances medios diarios en la perforación son del orden de $8,40 \mathrm{~m}$, de los que unos $2,50 \mathrm{~m}$ corresponden a cada pega.

Para la perforación de este último lote se han empleado, aproximadamente, $1,86 \mathrm{~kg} / \mathrm{m}^{3}$ de explosivos.

\section{Rovestimiemto}

La galería tiene sección, en forma de herradura, de $14,2 \mathrm{~m}^{2}$. Una vez revestida tendrá un diámetro de $3,5 \mathrm{~m}$. Para el hormigonado se han estudiado y proyectado una serie de instalaciones apropiadas a las particularidades que presentaba esta galería.

El equipo de hormigonado constituye un conjunto móvil automotor. En líneas generales este equipo se compone de los elementos siguientes:

1) Un cambio, tipo californiano, para el tren que transporta el hormigón, capaz de un largo suficiente de vía para estacionar en él una mezcladora Placy, montada sobre bogies y de $3,5 \mathrm{~m}^{3}$ de capacidad, procedente del exterior.

2) Una cinta transportadora, de unos $3 \mathrm{~m}$ de longitud, dotada de libertad suficiente para poder llevar su extremidad de descarga al tragante de la tolva estacionada en una de las vías del cambio californiano.

3) Otra cinta transportadora, de $10 \mathrm{~m}$ de longitud, que recoge el hormigón transportado por la precedente. Esta cinta tiene $500 \mathrm{~mm}$ de anchura y una velocidad de 1,60 metros/minuto.

4) Una tolva, de 750 litros de capacidad, situada sobre una plataforma que también soporta un aparato Placy, de 500 litros de capacidad, del que por aire comprimido se lleva el hormigón a los encofrados. Esta tolva se alimenta con una de las cintas anteriormente citadas.

Sobre la plataforma en que se instaló el aparato Placy se hallan los dispositivos de mando del conjunto del equipo de hormigonado y al alcance de un solo obrero, capaz de controlar todo el equipo de aparatos y hasta de mover el conjunto del tren de hormigonado.

Un dispositivo especial permite se acoplen los chasis de las palas, la cuba que impulsa el hormigón, el cambio californiano y los dos recipientes de aire comprimido, de 4.000 y 2.500 litros de capacidad respectivamente, que suministran el aire comprimido nece- 


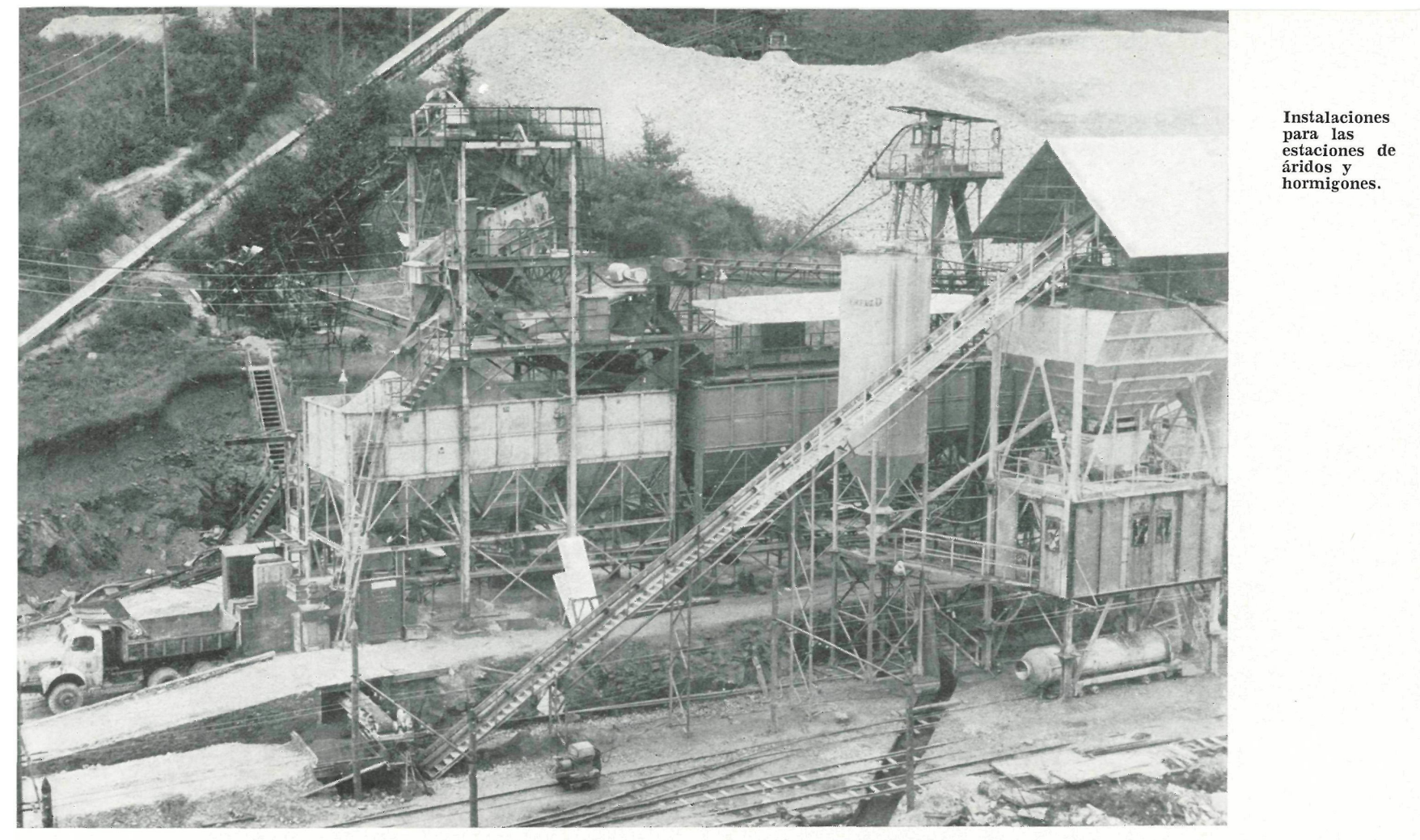

Transporte del hormigón por cinta.

Carga de una mezcladora Placy.
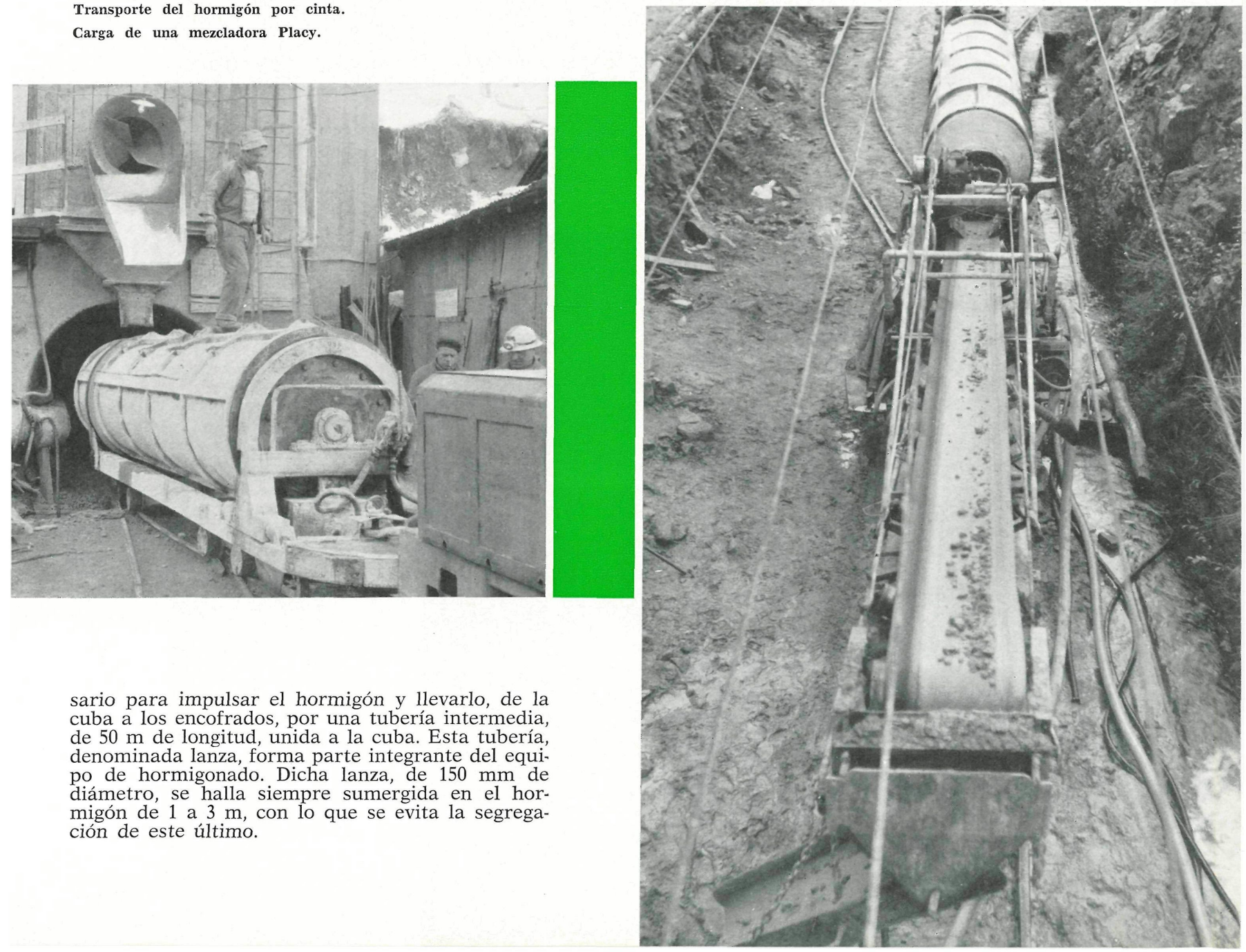

sario para impulsar el hormigón y llevarlo, de la cuba a los encofrados, por una tubería intermedia, de $50 \mathrm{~m}$ de longitud, unida a la cuba. Esta tubería denominada lanza, forma parte integrante del equipo de hormigonado. Dicha lanza, de $150 \mathrm{~mm}$ de diámetro, se halla siempre sumergida en el hormigón de 1 a $3 \mathrm{~m}$, con lo que se evita la segregación de este último.

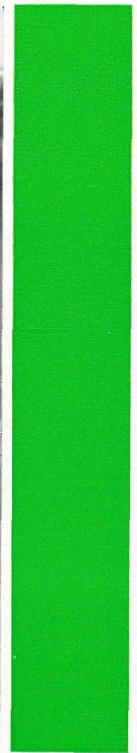




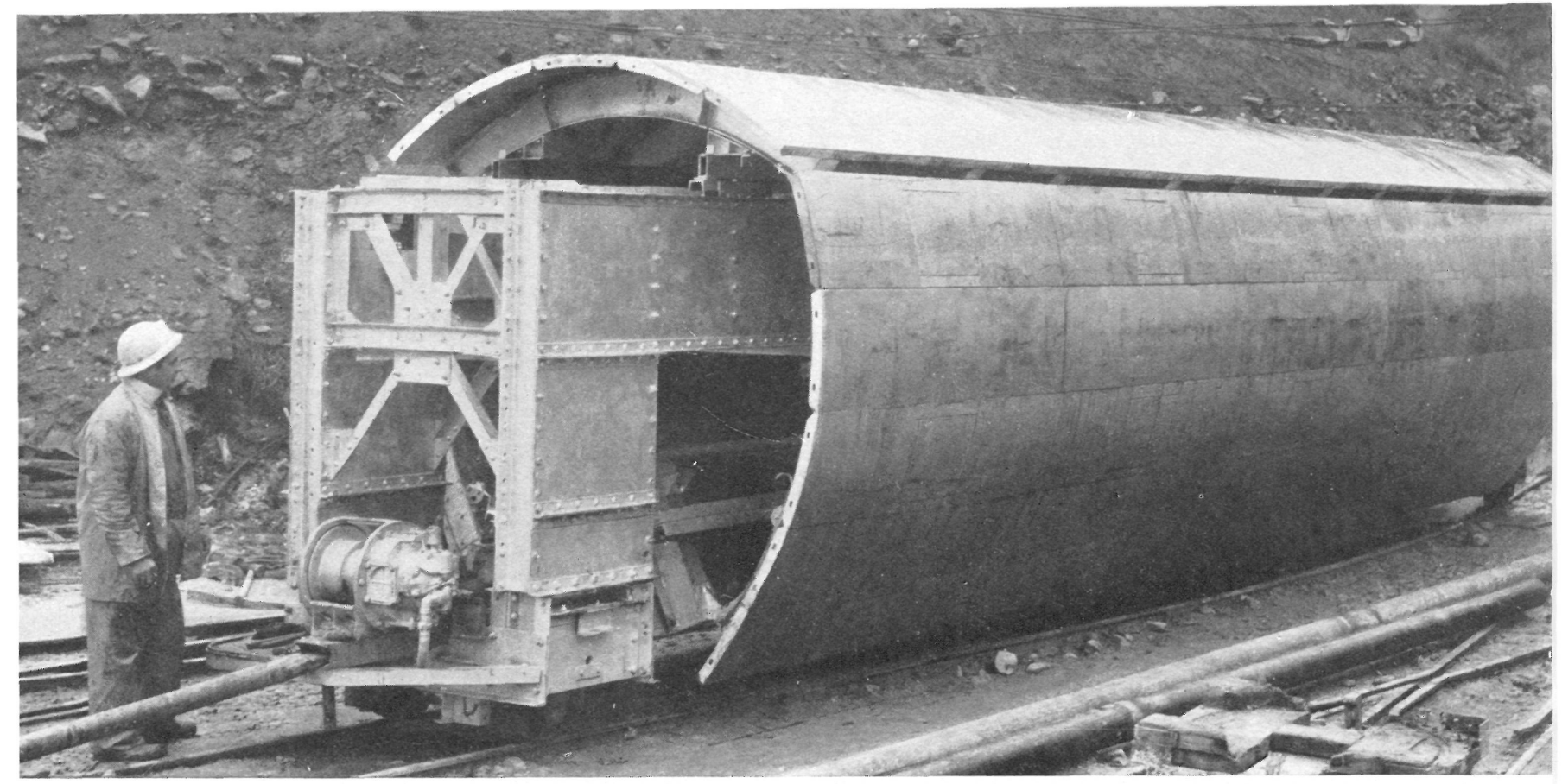

Encofrado móvil y plegado.

Con este equipo se ha logrado un rendimiento de $15,7 \mathrm{~m}^{3} / \mathrm{hr}$ de hormigón colocado en obra, es decir, un avance diario de $53 \mathrm{~m}$ en una galería de $3,5 \mathrm{~m}$ de diámetro. El equipo cuenta con cuatro mezcladoras tipo Placy, de $3,5 \mathrm{~m}^{3}$ de capacidad, que se van turnando sucesivamente en sus recorridos del exterior al frente de trabajo y de éste al exterior.

El tiempo muerto durante el cambio de mezcladoras, es decir, la llena que procede del exterior y la vaciada en el tajo, se aprovecha para lavar la lanza y evitar atoramientos perniciosos que retardan el ciclo de operaciones del hormigonado.

Los encofrados utilizados, metálicos, se componen de trozos o elementos, montados sobre carriles, de $10 \mathrm{~m}$ de longitud. Una de las empresas cuenta con nueve elementos de encofrado cuya longitud total se eleva a $90 \mathrm{~m}$,

Mandos para el control del equipo de hormigonado.

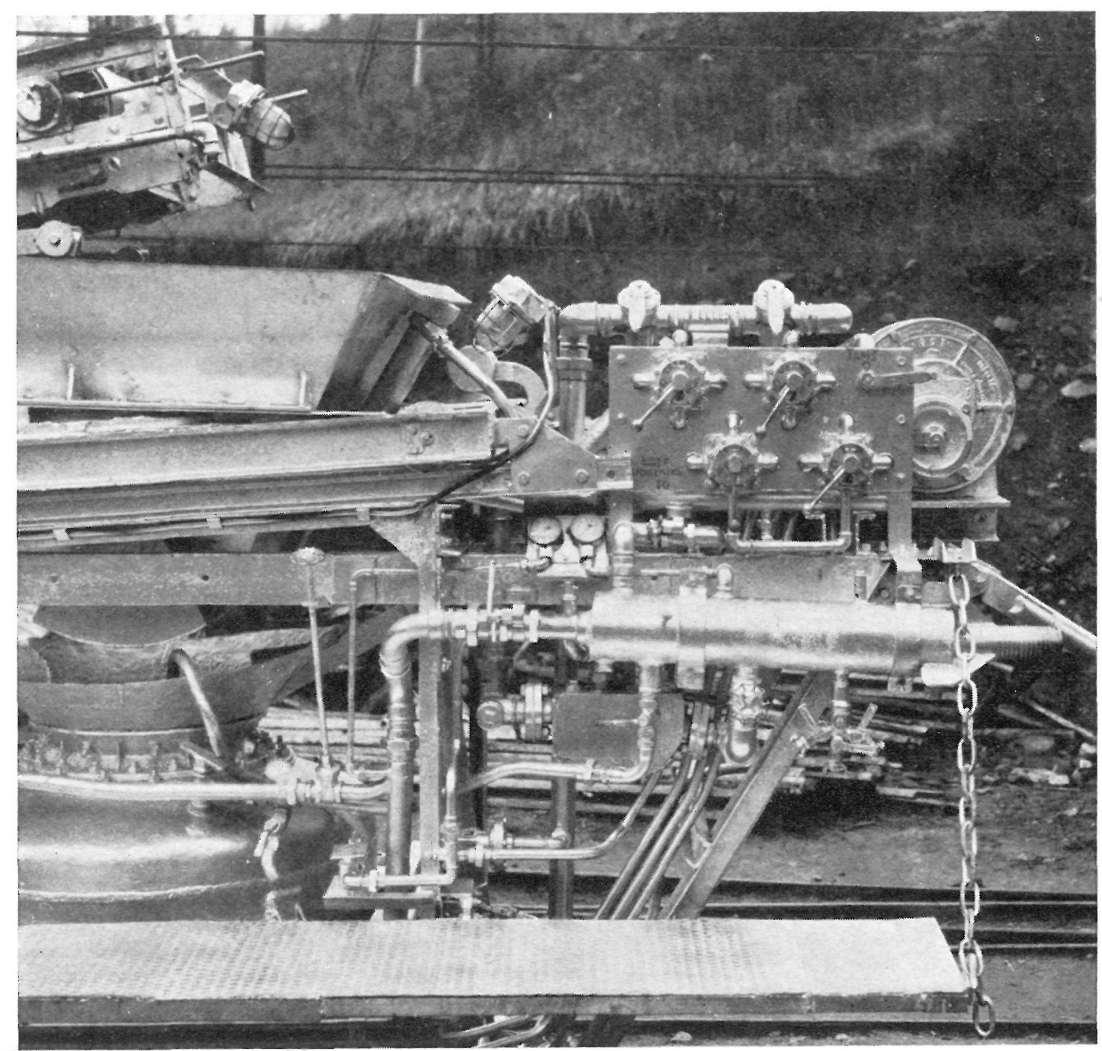

pero si el avance-como anteriormente se dijo-es de $50 \mathrm{~m}$ diarios y se exige $34 \mathrm{hr}$ antes de desencofrar, se comprenderá que el referido avance sufre un retardo por no disponer de suficiente número de elementos de encofrado.

La colocación y traslación a la nueva posición de cada elemento se ha verificado con sólo cuatro operarios, lo que supone una fuerte economía y reducción del número de operarios.

La galería Nèpes-Candes, de $3.50 \mathrm{~m}$ de diámetro $\mathrm{y}$ $10,15 \mathrm{~m}^{2}$ de sección libre una vez revestida, tiene una longitud total de 18.200 metros, desembocando en un arroyo cuyo curso será interceptado por un dique de retención, formando el embalse del que partirá otra galería, de $1.500 \mathrm{~m}$ de longitud, que llevará las aguas a la chimenea de equilibrio. Esta galería, revestida, deja una sección libre de $4 \mathrm{~m}$ de diámetro y $13,27 \mathrm{~m}^{2}$, que permite un gasto de $40 \mathrm{~m}^{3} /$ segundo.

Traducido y adaptado por $J$. Ugarte. 


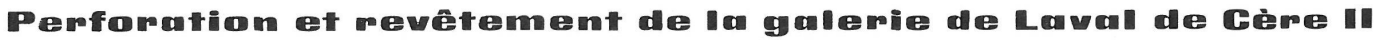 From an}

Georges Vié, ingénieur des mines

L'aménagement hydroélectrique de Cère II constitue un ensemble important exploité par EDF. Situé au Massif Central, montagneux, il présente les caractéristiques générales de ce type d'ouvrages, c'est-à-dire les galeries y sont la partie la plus importante.

Leur longueur étant très grande, tout l'effort tend à atteindre des vitesses maxima d'avancement, tant pour la perforation que pour le revêtement des galeries.

L'auteur étudie dans ce travail le matériel disponible capable d'assurer des cycles de répétition de la moindre période possible, et tend préférablement à faire une description des travaux réalisés et des méthodes employées pour chaque cas particulier, c'est-à-dire dans les zones où le terrain varie grandement.

Les moyens d'avancement ont pu être facilement comparés du fait que ce sont deux les entreprises auxquelles ont été confiés les travaux de perforation de la galerie principale.

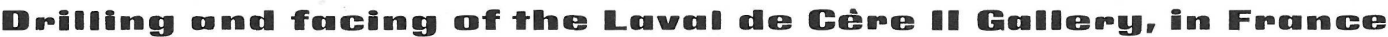

Georges Vié, mining engineer

The hydraulic development of Cère II is an important engineering project, that is being exploited by EDF. It is situated in the Central Massif, a mountainous region, and its feautres naturally correspond to the terrain where it is located.

The gallery is very long, and every effort has been made to achieve high rates of progress both in the drilling and facing work.

The author discusses the machinery that was used, and the measures adopted to take the greatest possible advantage of this equipment. The description is particularly detailed in relation to problems encountered on meeting changes in the rock and ground through which the gallery was drilled.

The rate of progress could be investigated in detail, since two separate contractors were entrusted with this aspect of the work, and pursued their task independently.

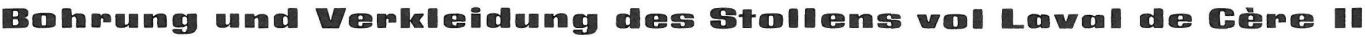 Frecu mike cich}

Georges Vié, Bergbauingenieur

Die Gewinnung von Elektrizität des Ceres II bildet einem wichtigen Komplex, der die Firma EDF fördert. Es liegt auf dem Zentralmassiv. Die Stollen sind den wichtigsten Teil dieses Baues.

Da seine Länge sehr gross ist, musste man viel arbeiten, sowohl in der Bohrung als auch in der Verkleidung der Stollen.

Zwei Baufirmen haben in diesem Stollen gearbeitet. 